\title{
Digital subtraction angiography in coronary artery bypass graft assessment: clinical applicability
}

\author{
R HAYWARD, ^ G J S HUNTER \\ From the Departments of Cardiology and of Diagnostic Imaging, ${ }^{\star}$ The Middlesex Hospital, London
}

SUMMARY Application of electrocardiogram gated digital subtraction angiography to the assessment of coronary artery bypass graft function was studied one week to eight years after bypass operation in ten unselected patients with recurrent chest pain. For the digital method, contrast was injected into the ascending aorta via a 4 or 5 French gauge catheter. The results of this technique were compared with those of selective graft and coronary angiography in the same patients by two independent observers.

Of twenty six grafts in the series, patency was confirmed in twenty one by both selective and digital angiography. The quality of graft run off, graded by each observer using a simple scoring system, demonstrated six points of inter observer disagreement when standard cineangiograms were used, compared with nine points of disagreement when digital images were used. Digital subtraction angiography provided useful graft visualisation, but was less good than conventional angiography at defining the native coronary circulation. The role of this promising new technique has yet to be established.

The number of patients receiving coronary artery bypass graft surgery will probably continue to increase. ${ }^{1}$ Symptom recurrence in over half the recipients within a decade ${ }^{2}$ and increasing attrition of graft patency rates during the second five postoperative years ${ }^{3}$ emphasise the need for a simplified method by which bypass graft function may be determined. Early optimism that intravenous digital subtraction angiography might provide the solution remains unconfirmed. ${ }^{4}$ The present method is derived from a radiographic film subtraction technique introduced fifty years ago ${ }^{5}$ and is based on computerised subtraction of a background or mask image from an image acquired after intravascular injection of contrast medium. Vascular conspicuity is sufficiently enhanced by digital background subtraction to enable aortic, cerebral, renal, and other relatively static arterial systems to be visualised after intravenous contrast injection. ${ }^{6}$ Images of coronary

Requests for reprints to Dr Roger Hayward, Department of Cardiology, The Middlesex Hospital, Mortimer Street, London WIN8AA.

Accepted for publication 21 June 1985 arteries and bypass grafts obtainable after intravenous injection of contrast are degraded by the effects of cardiac motion and by the appearance of contrast in underlying cardiac chambers, and such images are considered insufficiently reliable for clinical use. ${ }^{7}$ Accepting therefore that intra-arterial administration of contrast is necessary, ${ }^{467}$ this study explores the value of electrocardiogram gated digital subtraction with aortic root injection of contrast material via a small ( 4 or 5 French.gauge) catheter in bypass graft evaluation and assesses the feasibility of using this technique on patients during brief admissions to hospital.

\section{Patients and methods}

We studied ten unselected patients with recurrent chest pain after coronary artery bypass graft surgery. All gave informed consent; the project was approved by the hospital ethical committee. Glinical details are summarised in Table 1. Each patient underwent both conventional coronary arterial with bypass graft angiography and subsequent intra-arterial electrocardiogram gated digital subtraction angiography. 
Table 1 Clinical details of the 10 patients

\begin{tabular}{|c|c|c|c|c|c|c|}
\hline Patient & Age & Sex & $\begin{array}{l}\text { Coronary } \\
\text { disease }\end{array}$ & $\begin{array}{l}\text { Vessels } \\
\text { grafted }\end{array}$ & $L V E F$ & $\begin{array}{l}\text { Time since } \\
\text { operation }\end{array}$ \\
\hline 1 & 46 & $\mathbf{M}$ & $\begin{array}{l}\text { LAD severe } \\
\text { Cx severe } \\
\text { RCA mild }\end{array}$ & $\begin{array}{l}\text { LAD } \\
\text { CxM }\end{array}$ & $57 \%$ & 4 months \\
\hline 2 & 61 & $\mathbf{M}$ & $\begin{array}{l}\text { LAD severe } \\
\text { Cx severe } \\
\text { RCA severe }\end{array}$ & $\begin{array}{l}\text { LAD } \\
\text { CXM } \\
\text { RCA }\end{array}$ & $46 \%$ & 34 months \\
\hline 3 & 57 & $\mathbf{M}$ & $\begin{array}{l}\text { LAD severe } \\
\text { RCA severe } \\
\text { Cx moderate }\end{array}$ & RAD + PDA & - & 1 week \\
\hline 4 & 48 & $\mathbf{M}$ & $\begin{array}{l}\text { LMCA severe } \\
\text { LAD blocked } \\
\text { RCA severe }\end{array}$ & $\begin{array}{l}\text { LAD } \\
\text { CxM } \\
\text { RCA + Cx }\end{array}$ & $38 \%$ & 29 months \\
\hline $\begin{array}{l}5 \\
6\end{array}$ & $\begin{array}{l}61 \\
72\end{array}$ & $\begin{array}{l}\mathbf{M} \\
\mathbf{M}\end{array}$ & $\begin{array}{l}\text { LAD severe } \\
\text { LAD severe } \\
\text { Cx severe }\end{array}$ & $\begin{array}{l}\text { LAD } \\
\text { LAD } \\
\text { Cx } \\
\text { RCA }\end{array}$ & $\begin{array}{l}61 \% \\
49 \%\end{array}$ & $\begin{array}{l}8 \text { months } \\
16 \text { months }\end{array}$ \\
\hline 7 & 48 & $\mathbf{M}$ & $\begin{array}{l}\text { LAD blocked } \\
\text { RCA severe } \\
\text { Cx mild }\end{array}$ & LAD & - & 21 months \\
\hline 8 & 64 & $\mathbf{M}$ & $\begin{array}{l}\text { LAD blocked } \\
\text { Cx severe } \\
\text { RCA blocked }\end{array}$ & $\begin{array}{l}\text { LAD } \\
\text { CxM } \\
\text { RCA }\end{array}$ & $27 \%$ & 73 months \\
\hline 9 & 52 & $\mathbf{M}$ & $\begin{array}{l}\text { LAD blocked } \\
\text { Cx severe } \\
\text { RCA blocked }\end{array}$ & $\begin{array}{l}\text { LAD } \\
\text { Cx } \\
\text { RCA, PDA }\end{array}$ & $22 \%$ & 8 years \\
\hline 10 & 48 & $\mathbf{M}$ & $\begin{array}{l}\text { LAD severe } \\
\text { Cx severe } \\
\text { RCA severe }\end{array}$ & $\begin{array}{l}\text { LAD } \\
\text { CX } \\
\text { RCA }\end{array}$ & $44 \%$ & 8 months \\
\hline
\end{tabular}

Cx, circumflex artery; LAD, left anterior descending; LMCA, left main coronary; LVEF, left ventricular radionuclide ejection fraction; PDA, posterior descending coronary artery; RCA, right coronary artery; $M$, marginal branch, + , jump graft.

\section{CORONARY AND GRAFT CINEANGIOGRAPHY}

Conventional left ventriculography with selective coronary and bypass graft angiography was first undertaken by a femoral arterial Seldinger approach and 7 French gauge catheters. Approximately $10 \mathrm{ml}$ of Urografin 370 was injected by hand for each selective angiogram. Images were recorded on cine film at fifty frames per second with standard radiographic equipment (Angioskop, Siemens Ltd.). Patients were subsequently observed in hospital for up to 24 hours.

\section{DIGITAL SUBTRACTION ANGIOGRAPHY}

Patients fasted for four hours before the digital angiographic procedure, which was performed not more than eight days after conventional angiography. A 4 or 5 French gauge, $90 \mathrm{~cm}$, eight side hole, soft tip pigtail catheter (W. Cook, Europe or Radiplast, Sweden) was inserted into the femoral artery by a modified Seldinger technique and advanced to the aortic root under digital fluoroscopic control. Iohexol 350 (Nyegaard, Norway) (30 ml) was injected at $15 \mathrm{ml} / \mathrm{s}$ and a series of images was acquired in the left anterior oblique $35^{\circ}$ projection. A second series was obtained in the right anterior oblique $5^{\circ}$ projection. Image acquisition took place over the aortic root. The electrocardiogram and arterial pressure were monitored; full resuscitatory support was to hand. Patients were fully mobile within four hours of catheter removal.

The components of the digital subtraction system (DR 960, Technicare, Ohio, USA) are shown in Fig. 1. The principles involved in using this equipment for other purposes have been described elsewhere. $^{8-10}$ To minimise inaccurate pixel superimposition between mask and contrast images, the digital data acquisition sequence was performed with the patient in arrested respiration, so that much thoracic and lung movement artefact could be eliminated. To deal with the effects of cardiac motion and to maintain pixel registration, image acquisition was gated by the $\mathbf{R}$ wave of the patient's electrocardiogram. In addition, non-ionic contrast material was used to reduce possible involuntary movement on the part of the patient in response to osmolality related sensations imparted by conventional contrast materials. Images were acquired using a $15 \mathrm{~cm}$ field size and an exposure time of $40 \mathrm{~ms}$ per frame. An appropriate generator voltage was selected to ensure adequate $x$ ray beam penetration, in the range 75-105 kVp. Images were converted from analogue into a digital format with eight bits of information per pixel, that is 256 levels of grey. Due to limitations upon the rate of data transfer between the analogue to digital converter and the computer, a 256 by 256 matrix was chosen so that acquisition 


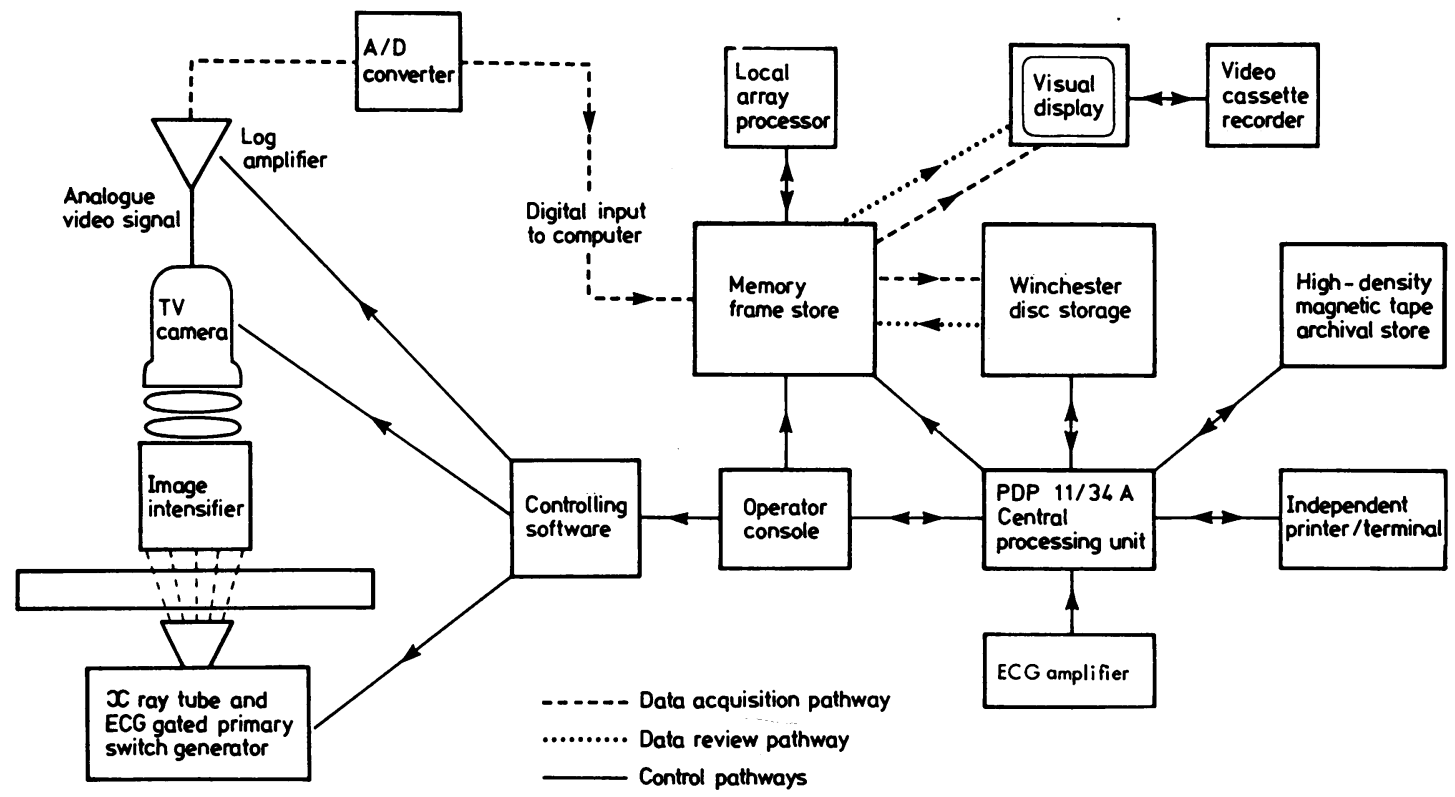

Fig. 1 Components of the digital subtraction angiography system. A/D converter, analogue to digital converter unit; PDP 11/34A central processing unit, a commercially available 16 bit minicomputer from Digital Equipment Corporation, USA.

rates up to 8.33 frames per second could be achieved. This matrix size yields a resolution of 0.6 $\mathrm{mm}$ per pixel over the field of view.

Six electrocardiogram gated images were acquired per cardiac cycle, each subseries being triggered by the $\mathbf{R}$ wave. Six cardiac cycles were imaged for each aortogram, of which two were obtained before contrast injection for subsequent use as masks. All images were stored on disc and archived to magnetic tape for future analysis. The best mask and corresponding contrast images were selected during a retrospective review of the series from each patient.

\section{DATA ANALYSIS}

Both authors independently assessed the cineangiograms of all ten patients, noting graft patency and giving a numerical score for the quality of runoff from each patent graft according to an arbitrary scale of 1, poor run-off; 2, moderate; and 3 good. The digital subtraction studies on the same patients were then similarly assessed by both observers.

\section{Results}

Fig. 2 is a representative subtracted angiographic frame from patient 7 . This frame, taken relatively early in the sequence from this aortogram, illustrates the digital image quality of this patient's right coronary artery and bypass graft.

The results of the graft scoring process are sum- marised in Tables 2 and 3. There was complete agreement on the issue of graft patency versus occlusion, both between observers and between techniques (Table 2). Differences emerged when the scoring system was used to assess graft run off

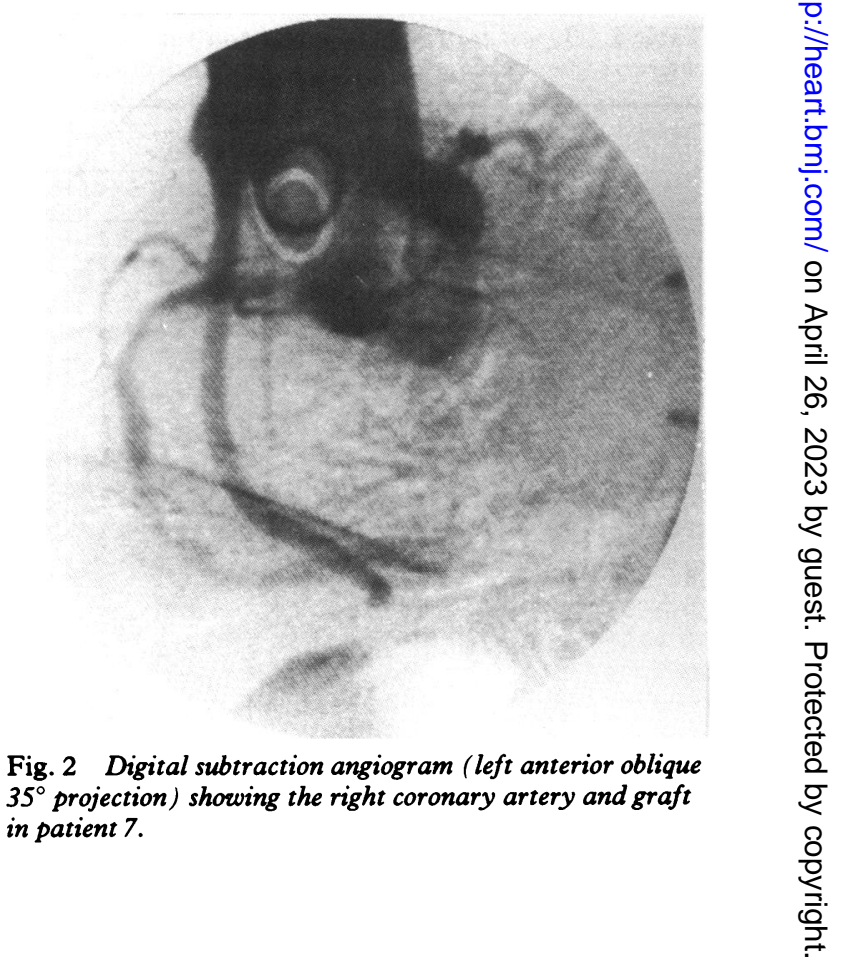


Table 2 Graft patency assessment on the basis of selective and digital angiograms (both observers were in agreement)

\begin{tabular}{|c|c|c|c|}
\hline \multirow[t]{2}{*}{ Patient } & \multirow{2}{*}{$\begin{array}{l}\text { Number of grafts } \\
\text { inserted at operation }\end{array}$} & \multicolumn{2}{|c|}{ Number of grafts seen on: } \\
\hline & & $\begin{array}{l}\text { Conventional } \\
\text { angiography }\end{array}$ & $\begin{array}{l}\text { Digital } \\
\text { angiography }\end{array}$ \\
\hline $\begin{array}{c}1 \\
2 \\
3 \\
4 \\
5 \\
6 \\
7 \\
8 \\
9 \\
10 \\
\text { Total }\end{array}$ & $\begin{array}{r}2 \\
3 \\
2 \\
3 \\
1 \\
3 \\
2 \\
3 \\
4 \\
3 \\
26\end{array}$ & $\begin{array}{r}2 \\
2 \\
2 \\
2 \\
1 \\
3 \\
2 \\
2 \\
2 \\
3 \\
21\end{array}$ & $\begin{array}{r}2 \\
2 \\
2 \\
2 \\
1 \\
3 \\
2 \\
2 \\
2 \\
3 \\
21\end{array}$ \\
\hline
\end{tabular}

(Table 3). In view of the subjective nature of this determination we did not consider it appropriate to apply objective methods of statistical analysis to these numerical values. Results however clearly indicate disagreement between observers in relation to bypass graft run off grading. With standard angiograms there were six points of disagreement between observers, these were restricted to three patients (marked with an asterisk in Table 3). With the digital method there were nine points of disagreement involving seven of the ten patients. The first observer assigned identical scores for graft run off on the basis of the two angiographic techniques for 18 of the 21 patent grafts (Table 3). Using digital data and standard angiograms the second observer as-

Table 3 Bypass graft run off independently assessed by two observers who studied selective and digital angiograms

\begin{tabular}{|c|c|c|c|c|c|c|}
\hline \multirow[t]{2}{*}{ Patient } & \multicolumn{3}{|c|}{ Conventional angiography } & \multicolumn{3}{|c|}{ Digital angiography } \\
\hline & \multicolumn{2}{|c|}{ Observer 1} & Observer 2 & \multicolumn{2}{|c|}{ Observer 1} & \multirow{2}{*}{$\frac{\text { Observer } 2}{2}$} \\
\hline 1 & $\begin{array}{l}3 \\
3\end{array}$ & $\begin{array}{l}\star \\
\star\end{array}$ & $\begin{array}{l}2 \\
2\end{array}$ & $\begin{array}{l}3 \\
3\end{array}$ & $\star$ & \\
\hline 2 & $\begin{array}{l}3 \\
3\end{array}$ & & $\begin{array}{l}3 \\
3\end{array}$ & $\begin{array}{l}2 \\
3\end{array}$ & & $\begin{array}{l}2 \\
2\end{array}$ \\
\hline 3 & $\begin{array}{l}2 \\
2\end{array}$ & & $\begin{array}{l}2 \\
2\end{array}$ & $\begin{array}{l}2 \\
2\end{array}$ & & $\begin{array}{l}2 \\
2\end{array}$ \\
\hline 4 & $\begin{array}{l}2 \\
1\end{array}$ & & $\begin{array}{l}2 \\
1\end{array}$ & $\begin{array}{l}2 \\
1\end{array}$ & & $\begin{array}{l}2 \\
1\end{array}$ \\
\hline 5 & 3 & & 3 & 3 & & 3 \\
\hline 6 & $\begin{array}{l}1 \\
1 \\
2\end{array}$ & $\begin{array}{l}\star \\
\star \\
\star\end{array}$ & $\begin{array}{l}2 \\
2 \\
3\end{array}$ & $\begin{array}{l}1 \\
2 \\
2\end{array}$ & $\star$ & $\begin{array}{l}1 \\
2 \\
3\end{array}$ \\
\hline 7 & $\begin{array}{l}2 \\
2 \\
3\end{array}$ & $\star$ & $\begin{array}{l}3 \\
2 \\
2\end{array}$ & $\begin{array}{l}2 \\
2 \\
3\end{array}$ & $\star$ & $\begin{array}{l}3 \\
2 \\
2\end{array}$ \\
\hline 8 & $\begin{array}{l}2 \\
1\end{array}$ & & $\begin{array}{l}2 \\
1\end{array}$ & $\begin{array}{l}2 \\
1\end{array}$ & $\star$ & $\begin{array}{l}3 \\
1\end{array}$ \\
\hline 9 & $\begin{array}{l}3 \\
3\end{array}$ & & $\begin{array}{l}3 \\
3\end{array}$ & $\begin{array}{l}2 \\
3\end{array}$ & $\star \star$ & $\begin{array}{l}3 \\
2\end{array}$ \\
\hline 10 & $\begin{array}{l}1 \\
2 \\
3\end{array}$ & & $\begin{array}{l}1 \\
2 \\
3\end{array}$ & $\begin{array}{l}1 \\
2 \\
3\end{array}$ & $\star$ & $\begin{array}{l}1 \\
3 \\
3\end{array}$ \\
\hline Totals & 46 & & 46 & 45 & & 44 \\
\hline
\end{tabular}

Scoring system: 3 , good run off; 2 , moderate run off; 1 , poor run off. $\star$ Point of disagreement between observers. signed the same run off score to 15 of these 21 grafts. There were nine instances of intra-observer disagreement for the run off scores ascribed by means of the two differing angiographic techniques, with intra-observer agreement in the remaining 33. A slight tendency towards underestimation of graft run off by digital angiography was apparent. Scores generated by this method were lower than those ascribed on the basis of conventional angiography in six instances though they were higher in three. Differences in graft run off score between the techniques were never more than one scoring point. Good quality images of the native coronary arterial system were obtained in seven of the 10 patients studied (Fig. 2). Presence of impaired left ventricular function in patients $4,8,9$, and 10 (Table 1) had no discernible impact on digital image quality.

Total irradiation to the patient during the digital angiographic study was $6.0 \mathrm{cG}$ entrance dose and 0.3 cG exit dose, including all positioning views. This resembles the dose administered during 30 chest radiographs and is one third to one quarter that received during a conventional coronary angiogram without graft injections. Digital angiography including all preliminaries took $20-30$ minutes.

There were no complications during either investigation, though one patient (case 9) with severely impaired left ventricular function was judged unfit to travel home four hours after digital angiography and needed overnight hospital admission.

\section{Discussion}

Results of this study provide grounds for optimism about the future usefulness of digital subtraction angiography in the investigation of patients after coronary artery bypass surgery. A means of bypass graft visualisation which does not require formal selective angiography is desirable; the technique described here approaches this goal. Its limitations remain substantial. Preliminary studies have indicated that bypass graft patency may not be displayed by digital subtraction angiography with intravenous and right atrial contrast injection; this was the case in eight of twenty six patent grafts previously investigated with right atrial contrast, ${ }^{7}$ and use of venous circuit injections in conjunction with right atrial contrast injection is now discontinued. Similar conclusions have been reached by others in relation to coronary vascular imaging ${ }^{46}$ although work is in progress to improve background subtraction methods and permit faster framing rates. ${ }^{6-11}$ A note of caution has recently been sounded by Levin and colleagues who point out that each new adaptation incorporated into future third generation digital subtraction angiography equipment may furnish new sources of arte- 
fact. ${ }^{11}$ For these reasons it was considered important to explore the potential of a currently available second generation device.

The technique we describe was good for evaluating graft patency; there were no errors in the assessment of graft patency in the present series despite quite poor graft run off in several cases. Details of graft function were not always clearly delineated. Interobserver disagreement in grading of graft run off was uncommon when standard angiograms were used (six instances), but somewhat more frequent with digital subtraction images (nine instances). Though this difference is clearly not statistically significant, it is possible that the precision with which graft function may be graded by digital angiograms may be less than that achieved with selective angiograms. Further experience will determine whether the enhanced conspicuity inherent in the technique of digital subtraction may prove sufficient to match the image quality currently offered by cineangiography with selective coronary opacification.

Because, when necessary, diseased coronary arteries with diameters of as little as $1 \mathrm{~mm}$ are currently grafted, the spatial resolving power of present digital subtraction equipment $(0.6 \mathrm{~mm})$ may become a limiting factor, particularly if some misregistration occurs through uncontrolled movement, despite the use of electrocardiogram gating and image acquisition during arrested respiration. It is possible that a slight though not significant tendency towards underestimation of run off with digital images may have occurred for this reason.

Unlike the situation following intravenous contrast injections, digital subtraction angiograms after intra-arterial injections are not affected by dispersion of the bolus of contrast material during passage from right atrium to aorta. Though useful information on left ventricular function is obtainable by digital subtraction after intravenous contrast injection, ${ }^{10}$ imaging of coronary bypass grafts and native arteries is less satisfactory. ${ }^{7}$ With the technique we describe in which there was arterial injection of contrast, good quality images of the coronary circulation can be obtained despite impaired cardiac function. Since only small gauge catheters are used and selective injection is not required, the procedure is less invasive than a conventional graft angiogram. The period of supervision needed afterwards is short and overnight hospital stay is usually unnecessary. This has advantages for the patient and the centre which in view of this simplified technique may be able to add bypass graft assessment to the range of investigations that it performs.

\section{Conclusion}

The place of intra-arterial digital subtraction angiography has been investigated in the assessment of coronary artery bypass graft patency and run off. Despite minor differences between results achieved by this means and those from standard selective angiography, results are encouraging. Present facilities for investigation of patients after coronary bypass surgery are under increasing pressure. Intra-aortic electrocardiogram gated digital subtraction angiography may provide an acceptable method for studying bypass graft function, with reduced invasiveness, shortened procedure time, and a potential saving in cost. A more extensive investigation of its place in the review of early and late results of bypass surgery is indicated.

We thank Dr Richard Emanuel and Mr Tom Treasure for their help and advice in the preparation of this paper, and Dr Howard Swanton and Mr Marvin Sturridge for allowing access to patients under their care.

Dr Hunter was supported in this work by the Special Trustees of the Middlesex Hospital.

\section{References}

1 Jennett B, et al. Consensus development conference: coronary artery bypass grafting. $\mathrm{Br} \mathrm{Med} \mathcal{f} 1984$; 289: 1527-9.

2 Lawrie GM, Morris GC, Jr, Calhoon JH, et al. Clinical results of coronary bypass in 500 patients at least 10 years after operation. Circulation 1982; 66 (suppl I): $1-5$.

3 Grondin CM. Late results of coronary artery grafting: Is there a flag on the field? $\mathcal{F}$ Thorac Cardiovasc Surg 1984; 87: 161-6.

4 Levin DC. Digital subtraction angiography: myths and reality. Radiology 1984; 151: 803.

5 Ziedses des Plantes BG. Subtraktion. Eine röntgenographische Methode zur separaten Abbildung bestimmter Teile des Objekts. Fortschritte auf dem Gebiete der Röntgenstrahlen und der Nuklearmedizin 1935; 52: 69-79.

6 Riederer SJ, Kruger RA. Intravenous digital subtraction: a summary of recent developments. Radiology 1983; 147: 633-8.

7 Hunter G, Walton S, Hayward R, Swanton RH, Emanuel $R$. Digital subtraction angiography: a screening procedure for patency of coronary artery bypass grafts [Abstract]. Br Heart F 1985; 53: 105.

8 Harrington DP, Boxt LM, Murray PD. Digital subtraction angiography: overview of technical principles. $A f R$ 1982; 139: 781-6.

9 Raphael M. Digital subtraction angiography. Current medical literature. Cardiovascular Medicine 1983; 2: 5-7.

10 Greenbaum RA, Evans TR. Investigation of left ventricular function by digital subtraction angiography. $\mathrm{Br}$ Heart f 1984; 51: 163-7.

11 Levin DC, Schapiro RM, Boxt LM, Dunham L, Harrington DP, Ergun DL. Digital subtraction angiography: principles and pitfalls of image improvement techniques. $A f R$ 1984; 143: 447-54. 